\title{
Brasileiros Ilustres: letras, armas, virtudes
}

\author{
Illustrious Brazilians: letters, weapons, virtues
}

OLIVEIRA, Maria da Glória de. Escrever vidas, narrar a história: a biografia como problema historiográfico no Brasil oitocentista. Rio de Janeiro: Editora FGV, 2011, 212 p.

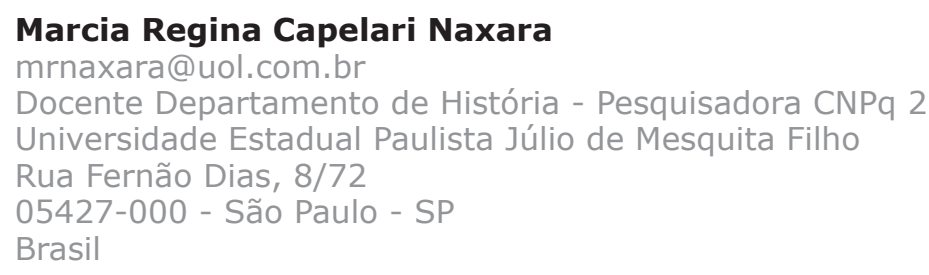

Palavras-chave

Brasil; Biografia; Historiografia do século XIX.

Keywords

294

Brazil, Biography; $19^{\text {th }}$ century historiography. 
São várias as perspectivas pelas quais a historiografia produzida no e sobre o Brasil no século XIX tem sido revisitada. Em Escrever vidas, narrar a história, Maria da Glória de Oliveira elabora, de forma perspicaz, indagações sobre o gênero biográfico, objeto complexo e suscetível a armadilhas, em especial se encarado de forma linear. Complexidade que só faz crescer quando a associação estabelecida a partir do título, qual seja a de "narrar a história" ao "escrever vidas", é também enviada à história da nação e da nacionalidade, estreitamente vinculadas a questões identitárias e de pertencimento que, no registro do político, esbarram no plano das sensibilidades. Questões que, como o seu trabalho bem demonstra - vidas narrando a história, "a biografia como problema historiográfico no Brasil oitocentista" -, podem parecer simples quando vislumbrados somente em termos aparentes.

A mobilização bibliográfica e a arquitetura do texto, elaborado com rigor conceitual, conduzem o leitor pelos meandros da construção do campo historiográfico no século XIX, ou melhor, pelas diversas formas de apreensão do histórico, pensado em termos de temporalidade e de representação "do curso dos acontecimentos como totalidade dotada de sentido" (OLIVEIRA 2011, p. 16), para o que ressalto a referência a Humboldt e ao regime de historicidade "em que o futuro passaria a ser a categoria preponderante" (OLIVEIRA 2011, p. 17), tal como formulado por Hartog. Forma de temporalidade que, como trabalhado pela autora a partir de Catroga, deixava em aberto o "problema acerca do papel dos indivíduos" na história, por sua vez, "concebida como agente do destino humano e do progresso social" (OLIVEIRA 2011, p. 17).

Se consideramos o Instituto Histórico e Geográfico Brasileiro (IHGB) foco central da análise da autora - como lugar privilegiado da construção de um passado para o Brasil, efetivado tanto pela concepção de um projeto de escrita da sua história, como da produção literária por que transitava grande parte de seus associados, pode-se inferir essa abertura e permanência nas relações indivíduo/sociedade. A procura e o estabelecimento de mitos de origem eram largamente compartilhados em termos da busca do estabelecimento de caracteres identitários comuns; procura realizada como viagem ao passado para a elaboração de origens e desenrolar da história, tanto em termos políticos para o presente, como lançada para um futuro distante de consolidação numa ideia que somasse o país/paisagem Brasil que se projetava. Nesse sentido, o trabalho de Oliveira acompanha a constituição do "problema historiográfico" na forma como elaborado pelo Instituto, bem como as formas como a biografia e a escrita da história se relacionavam, ou seja, o lugar que tiveram em termos do estabelecimento do que poderia ser "verdade" com relação à, nem sempre clara, proposição de alcançar precisão e veracidade sobre o passado, a ser, paulatinamente, esclarecido com a formação do panteão daqueles que marcaram presença ativa na construção da nação.

Pode-se lembrar que a escolha que recaiu sobre a proposta de Karl Friedrich Phillip von Martius, "Como se deve escrever a história do Brasil", em sua relação com a de Henrique Julio de Wallenstein, "Memória sobre o melhor plano de se escrever a história antiga e moderna do Brasil segundo a proposição 
do Instituto Histórico e Geográfico Brasileiro", não é despida de significado, já que Wallenstein estipulava a organização da história da nação a partir da sua cronologia dividida em décadas, enquanto que Martius apontava para a procura e estabelecimento de uma gênese, seguida da formação do país pela colaboração das três raças que aqui se estabeleceram: indígenas autóctones, portugueses colonizadores e negros introduzidos na condição de escravos, bem como a defesa da ordem monárquica. Procura não somente de inícios, mas de caminhos percorridos, pela organização documental capaz de estabelecer "verdades" que esclarecessem as linhas mestras de formação e afirmação do Brasil pelas características identitárias de sua natureza e de seu povo.

Ao colocar, na Introdução, a problemática central que orientou suas reflexões, Oliveira apresenta a organização do texto em quatro capítulos: o primeiro, "O presente do passado nos exemplos da história", é dedicado ao estudo do "lugar" da biografia no projeto da escrita de uma história do Brasil no âmbito do IHGB, ou seja, de como a formação de uma galeria de notáveis poderia colaborar na apreensão e compreensão do passado e, simultaneamente, na construção do futuro do país/nação Brasil; o segundo está voltado para os intentos realizados para a busca de "verdades" do passado, pela depuração dos escritos e documentos que o informam, pela correção de inexatidões e pela definição de critérios "de eleição das vidas memoráveis" (OLIVEIRA 2011, p. 32). Na continuidade, ao explorar a elaboração do "panteão de papel do IHGB", elabora a relação história e história literária do ponto de vista do Instituto, 296 formado, ao menos em parte, por escritores simultaneamente interessados na literatura e na história e em como ambos os gêneros podiam ser aproximados quando se tratava de escrever a história pátria. No quarto e último capítulo aborda as "articulações entre passado, presente e futuro", no que a exemplaridade da vida passada pudesse constituir força moralizadora em termos do futuro, na perspectiva de temporalidade então adotada. Há que se levar em conta, neste caso, como acentua a autora, a dinâmica do Instituto ao longo de sua existência e os debates que tiveram lugar a propósito da exemplaridade fornecida pelos grandes vultos, ou seja, a consideração de sua suficiência ou não quando se tratava de conhecer a sociedade brasileira, em que, nas palavras do sócio Alfredo do Nascimento, despontava "enorme legião de 'filhos da pobreza' e 'náufragos do mundo'" (OLIVEIRA 2011, p. 33), pouco ou nada contemplados nesse vínculo de vidas biografadas, história e nação.

Assinalo a presença, no final do volume, do anexo "Quadro de biografias da Revista do Instituto Histórico e Geográfico Brasileiro", que inclui, "além dos textos publicados na seção de Biografias de brasileiros ilustres, todos os artigos identificados pelo título, ou contendo as expressões 'biografia', 'apontamentos biográficos' ou 'apontamentos sobre a vida e obras [...]'" (OLIVEIRA 2011, p. 197-209), perfazendo 165 itens, elaborado pela autora e oferecido ao leitor.

Chamo a atenção para alguns pontos que contribuem para abalizar a importância deste estudo que explora e esquadrinha, de forma exemplar, a documentação do IHGB na sua relação com a bibliografia sobre o Instituto e as reflexões sobre a história do período e sobre o período: construção de uma 
memória para o país; persuasão pela exemplaridade; erudição como elemento fundamental da produção do conhecimento histórico; crítica das fontes; letras, armas e virtudes como elementos de distinção; aproximações entre história e história literária; o lugar da história no século XIX entre biografia, memória e experiência da história.

Oliveira inicia pela recuperação do debate que marcou a criação do IHGB, tanto em termos de uma aproximação da intelectualidade à monarquia, como da construção de um lugar de fala e elaboração do discurso sobre a pátria Brasil, que se sobrepusesse àquele que vinha sendo divulgado por estrangeiros. Valendo-se dos ensinamentos e herança dos antigos, objetivava-se narrar a vida dos grandes homens e construir, sobre bases fidedignas e com exatidão, uma memória para as gerações vindouras - caráter primordial, portanto, de testemunho e instrução. A autora recupera, sempre com atenção às ambivalências e ambiguidades que atravessam os diferentes discursos, a presença dos antigos na formulação do nascimento da história como rito de recordação e interdito ao esquecimento e apagamento pelo tempo, tal como formulado por Heródoto além da projeção futura do ajuizamento da equidade que então se procurava.

Oliveira demonstra, ao longo do segundo capítulo, que "expurgar os erros e preencher as lacunas da nossa história" (OLIVEIRA 2011, p. 77), ou seja, buscar métodos críticos que orientassem a elaboração do discurso histórico foi lema entre os integrantes e fizeram parte de amplo debate dentro do IHGB - a prova documental, a definição de seu estatuto de autenticidade e veracidade, a depuração da fábula e das verdades sobre ela estabelecidas, assim como com relação à ficção, já que se objetivava a obtenção de um conhecimento com a chancela de ciência. É exemplar, nesse sentido, a discussão ocorrida em torno da "veracidade da viagem do português Diogo Álvares Corrêa e da índia Paraguaçu ao reino da França, onde teriam se casado sob as bênçãos de Henrique II e de Catarina de Médicis" (OLIVEIRA 2011, p. 90), sobre o qual Varnhagen escreveu a dissertação "O Caramuru perante a história".

A virtude foi instituída critério fundamental para a escolha dos possíveis biografados; distinção a que se junta o domínio das letras e das armas - três qualidades essenciais. Elementos colocados, em conjunto, na construção e defesa da nação, que podia incluir "varões ilustres", ainda que não fossem brasileiros por nascimento, mas que tivessem aqui passado grande parte de suas vidas, e contassem com o feito de "ações gloriosas" (OLIVEIRA 2011, p. 100). Para a autora, com base na bibliografia compulsada, a fórmula utilizada evidencia sua natureza política, de forma a predominar no quadro de biografados distintos, os "funcionários de carreira do Estado e os religiosos", constituindo uma "espécie de galeria de espelhos que refletia e se confundia com o próprio quadro de fundadores e membros do IHGB", uma vez que, na sua maior parte, eram "servidores e dignitários do Império, a maioria com formação em Coimbra, nos cursos de preparação para a carreira jurídica ou das armas" (OLIVEIRA 2011 p. 107).

Constituíram desdobramentos dessa demarcação de homens ilustres, os projetos assentados na compilação de antologias poéticas acompanhadas dos 
dados biográficos dos poetas. Nas palavras da autora, colocava-se a necessidade de "inventariar o passado literário da nação", ensaiado por Cunha Barbosa, no seu Parnaso brasileiro (1829-1832), que teve continuidade com o Parnaso brasileiro (1843-1848) de Pereira da Silva e com o Florilégio da poesia brasileira (1846-1872), de Varnhagen. Movimento que teria encontrado na História da literatura brasileira (1888), de Silvio Romero, uma primeira sistematização. A fundação de uma historiografia literária conteria elementos indicativos de brasilidade e, para trabalhar esses primeiros empreendimentos de escrita e narrativa das coisas do Brasil - na forma de antologias e/ou coleções - a autora mobiliza bibliografia significativa, relativa tanto às relações das manifestações poéticas com a história, já que se tratava de colecionar os primeiros escritos sobre o Brasil e Ihes conferir organicidade, como aos embates que tiveram lugar para a definição dos merecedores de presença no inventário do passado literário da nação, pela busca do esclarecimento de suas histórias de vida. Tarefa difícil, tendo em vista o intento em diferenciar e destacar as manifestações literárias do Brasil em relação às de Portugal, e em encontrar documentos e informações biográficas de tempos remotos.

A problemática é trabalhada em termos da historicização do próprio conceito de nação à época, do projeto romântico, do conceito moderno de literatura e, também, pela perspectiva de que a história, no século XIX, definiu o lugar do empírico. Operação que transita entre história e esquecimento, na formação do panteão que historiaria a nação - a literatura é testemunho de existência e a 298 escolha ocorre entre os melhores ou, muitas vezes, os simplesmente existentes. Ainda uma vez Varnhagen e o seu Florilégio da poesia brasileira constituíram material importante para a discussão dos pressupostos que presidiram os caminhos de definição de singularidades que pudessem dizer do Brasil em suas características históricas essenciais e genealógicas, além de trazer à luz debates e controvérsias que tiveram lugar na Revista do Instituto.

Ao abordar as relações entre biografia, memória e experiência da história, Oliveira recupera a intenção do IHGB quanto ao lugar declarado de guardião e crítico dos testemunhos do passado. Intenção problemática, dada a dupla colocação: estabelecimento fidedigno dos acontecimentos do passado e produção de sentido na sua narrativa. Tarefa avaliada pelos contemporâneos como crescentemente complexa: como lidar com a pluralidade de perspectivas, testemunhos e certificações, para pensar o ponto de vista do historiador e, mais do que isso, definir a verdade em história. Mais complexas, ainda, quando se aproxima a história do sentimento patriótico e, simultaneamente, se a arvora em estabelecedora da(s) verdade(s) do passado.

Finalizo por realçar o diálogo, por afinidades de interesse e interpretação, com autores que têm buscado a compreensão da complexidade abrigada no IHGB, em termos da produção intelectual sobre o Brasil no século XIX e os modos objetivados para a apreensão da sua história. Verifica-se, entre outras, a presença das pesquisas desenvolvidas por Lucia Paschoal Guimarães e, em especial, as de seus orientadores: Temístocles Cézar (mestrado), que prefacia o volume com texto que merece atenção, e Manoel Luiz Salgado Guimarães 
(doutorado), lembrado em dedicatória. Com os mesmos, Maria da Glória de Oliveira estabelece diálogo de aprendizado que revela, sem dúvida, a herança do rigor profissional de ambos, e, também, a autonomia adquirida no privilégio da convivência e troca intelectual. 